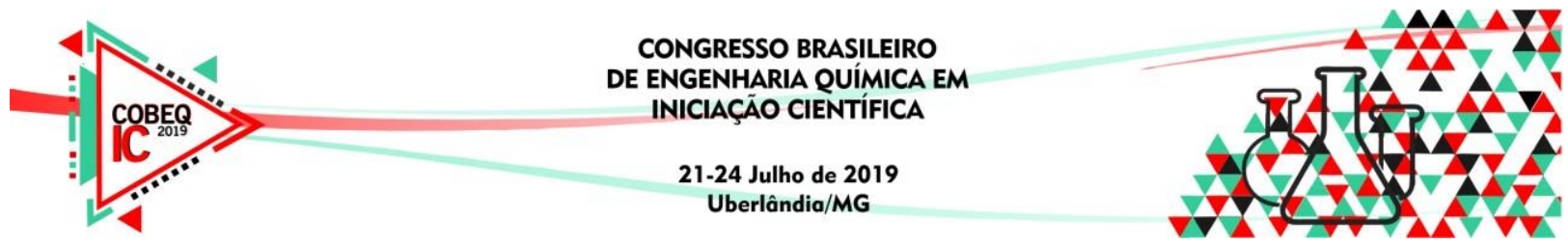

\title{
CARACTERIZAÇÃO DE LIPASE DE Rhizopus oryzae QUANTO AOS VALORES ÓTIMOS DE PH E TEMPERATURA UTILIZANDO DELINEAMENTO COMPOSTO CENTRAL ROTACIONAL (DCCR)
}

\author{
B. M. SILVA ${ }^{1}$, V. G. BATISTA ${ }^{1}$, J. B. B. LASCHI ${ }^{1}$, M. O. CERRI ${ }^{1}$ e A. V. PAULA ${ }^{1}$ \\ ${ }^{1}$ Universidade Estadual "Júlio de Mesquita Filho" \\ E-mail para contato: beatriz.m.silva@unesp.br, ariela.veloso@unesp.br
}

\begin{abstract}
RESUMO - Atualmente, os processos catalisados por enzimas são amplamente utilizados, principalmente pelo fato de oferecerem maior estabilidade reacional e especificidade quando comparados às reações químicas. Nesse contexto, uma bioconversão que pode ser citada é de obtenção de triglicerídeos dietéticos do tipo MLM, que são óleos e gorduras estruturados para conter ácidos graxos de cadeia média (M) nas posições sn-1 e sn-3 e de cadeia longa (L) na posição sn-2. Tais modificações podem ser feitas empregando biocatalisadores, nesse caso lipases 1,3 específicas, aplicadas em reações de acidólise enzimática, sendo importante estudar as características da enzima livre para a posterior comparação com os derivados imobilizados. Portanto, o presente trabalho caracterizou a enzima livre de Rhizhopus oryzae quanto aos valores ótimos de $\mathrm{pH}$ e temperatura utilizando planejamento experimental do tipo DCCR, os resultados obtidos de temperatura ótima em $39^{\circ} \mathrm{C}$ e do $\mathrm{pH} 6,8$ foram próximos aos descritos pela literatura.
\end{abstract}

\section{INTRODUÇÃO}

As lipases são enzimas da classe das hidrolases (EC 3.1.1.3, triacilglicerol acilhidrolases) que atuam na hidrólise de óleos e gorduras para liberação de ácidos graxos livres e glicerol. Podem ser obtidas de fontes animais, vegetais ou microbianas, e são amplamente utilizadas em sínteses orgânicas e processos biotecnológicos. Dessa forma, essas enzimas merecem destaque por serem as únicas capazes de hidrolisar triacilgliceróis, incluindo as reações inversas, que podem ser combinadas e classificadas em reações de transesterificação (acidólise, alcoólise e interesterificação) (BASSAN, 2017; CIPOLATTI, 2015).

Ademais, possuem alta especificidade, fator relacionado à sua quimio-regio e enantiosseletividade, o que resulta em melhor desempenho em reações de síntese quando comparadas a processos químicos (BASSAN, 2017). Nesse contexto, o estudo dessas enzimas em sua forma livre é interessante para que seja possível comparar suas características nativas com as observadas quando imobilizadas. 


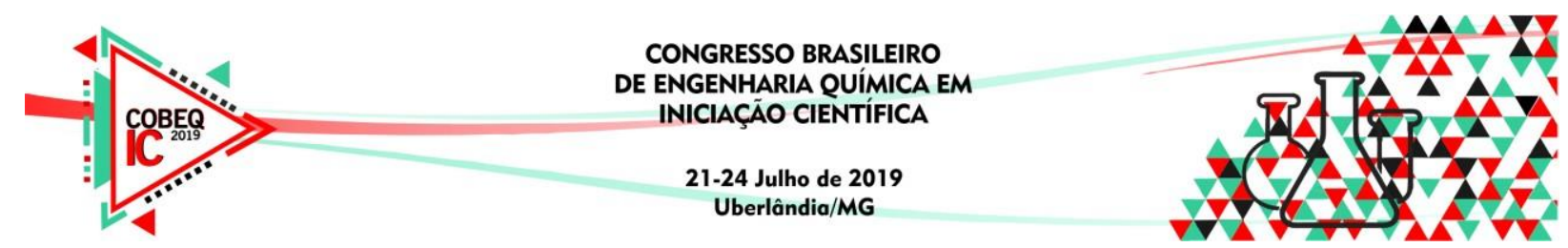

\section{OBJETIVO}

O presente trabalho caracterizou a enzima de Rhizopus oryzae em sua forma livre quanto a $\mathrm{pH}$ e temperatura ótima por meio de planejamento experimental, utilizando delineamento composto central rotacional (DCCR).

\section{MATERIAL E MÉTODOS}

\subsection{Material}

Os experimentos do presente trabalho foram efetuados utilizando lipase de Rhizopus oryzae, de grau alimentício (Prozyn, São Paulo). Os demais reagentes foram de grau analítico.

\subsection{Procedimentos experimentais}

\subsubsection{Determinação de atividade hidrolítica}

Foi determinada pelo método de retrotitulação, empregando-se emulsão de azeite de oliva (PAULA, 2012). Tal emulsão foi preparada com 50\% (m/m) de azeite, $50 \%(\mathrm{~m} / \mathrm{m}) \mathrm{de}$ água destilada e $7 \%(\mathrm{~m} / \mathrm{m})$ em relação à massa de água de goma arábica. A reação ocorreu em banho-maria com agitação suave, a $37^{\circ} \mathrm{C}$ por 5 minutos. A reação foi paralisada adicionando $10 \mathrm{~mL}$ de solução de etanol, acetona e água, 1:1:1 (v/v/v). Após, foi adicionado $10 \mathrm{~mL}$ de $\mathrm{KOH}(0,05 \mathrm{M})$. Foi realizada a titulação com $\mathrm{HCl}(0,05 \mathrm{M})$. A atividade hidrolítica foi determinada de acordo com a equação 1:

$$
A(\mu \mathrm{mol} / \mathrm{g} \min )=\frac{\left(V_{\text {branco }}-V_{\text {amostra }}\right) * C_{H C l} * 1000}{\text { tempo } * \text { massa }}
$$

Onde $\mathrm{V}_{\text {branco }}=$ volume de $\mathrm{HCl}$ utilizado no branco da reação $(\mathrm{mL}), \mathrm{V}_{\text {amostra }}=$ volume de $\mathrm{HCl}$ utilizado na amostra contendo enzima $(\mathrm{mL}), \mathrm{C}_{\mathrm{HCl}}=$ concentração real de $\mathrm{HCl}(\mathrm{Mol} / \mathrm{L})$, tempo $=$ tempo de reação $(\min )$, massa $=$ massa de enzima adicionada ou massa de derivado imobilizado (g).

\subsubsection{Determinação dos valores ótimos de pH e temperatura}

Foram realizados 12 ensaios para o estudo dos valores ótimos de $\mathrm{pH}$ e temperatura da lipase de Rhizopus oryzae imobilizada em sabugo de milho, tratando-se de um planejamento fatorial $2^{3} \mathrm{com} 4$ pontos centrais. Para cada ensaio, realizado de maneira aleatória, a influência do $\mathrm{pH}$ e da temperatura na atividade da enzima foi determinada pela reação de hidrólise do azeite de oliva de acordo com a metodologia descrita no 3.2.1. A análise estatística dos resultados foi realizada através do programa computacional Protimiza Experimental Design. 


\section{RESULTADOS E DISCUSSÃO}

\subsection{Estudo do efeito do pH e da temperatura na atividade da enzima livre}

Para avaliar a influência da temperatura e do $\mathrm{pH}$ na atividade enzimática da lipase de Rhizopus oryzae foram realizados 12 experimentos utilizando o delineamento composto central rotacional (DCCR), a matriz experimental está representada na tabela 1.

Tabela 1 - Matriz do planejamento experimental DCCR: variáveis independentes ( $\mathrm{pH}$ e temperatura) e a variável dependente de resposta (atividade enzimática, U/g) para cada ensaio.

\begin{tabular}{|c|c|c|c|c|c|}
\hline \multirow{2}{*}{ Ensaios } & \multicolumn{2}{|c|}{ Variáveis Codificadas } & \multicolumn{2}{c|}{ Variáveis Reais } & Resposta \\
\cline { 2 - 6 } & $\mathbf{p H}$ & $\mathbf{T ~}\left({ }^{\circ} \mathbf{C}\right)$ & $\mathbf{p H}$ & $\mathbf{T}\left({ }^{\circ} \mathbf{C}\right)$ & Atividade $(\mathbf{U} / \mathbf{g})$ \\
\hline 1 & -1 & -1 & 6,0 & 35 & 22372,55 \\
\hline 2 & 1 & -1 & 9,0 & 35 & 9588,24 \\
\hline 3 & -1 & 1 & 6,0 & 45 & 24591,88 \\
\hline 4 & 1 & 1 & 9,0 & 45 & 7582,78 \\
\hline 5 & $-1,41$ & 0 & 5,4 & 40 & 23240,85 \\
\hline 6 & 1,41 & 0 & 9,6 & 40 & 4271,29 \\
\hline 7 & 0 & $-1,41$ & 7,5 & 33 & 24276,60 \\
\hline 8 & 0 & 1,41 & 7,5 & 47 & 15137,96 \\
\hline 9 & 0 & 0 & 7,5 & 40 & 28265,90 \\
\hline 10 & 0 & 0 & 7,5 & 40 & 28265,90 \\
\hline 11 & 0 & 0 & 7,5 & 40 & 26847,06 \\
\hline 12 & 0 & 0 & 7,5 & 40 & 28420,51 \\
\hline
\end{tabular}

Após o tratamento de dados no Protimiza Experimental Design foi gerada a tabela 2 que apresenta os coeficientes de regressão, erros padrão, os valores de $t$ calculado e de p-valor para a atividade obtida nos ensaios. Os dados tabelados foram utilizados na construção do modelo matemático descrito pela equação 1 .

$$
Y_{1}=27949,84-7077,55 x_{1}-7271,34 x_{1}^{2}-1588,76 x_{2}-4295,73 x_{2}{ }^{2}
$$

Em que $\mathrm{x} 1=\mathrm{pH}, \mathrm{x} 2=$ Temperatura $\left({ }^{\circ} \mathrm{C}\right)$ e $\mathrm{Y} 1=$ Atividade $(\mathrm{U} / \mathrm{g})$.

Tabela 2 - Resultados dos coeficientes de regressão, erros padrão, os valores de t calculado e de p-valor no estudo do efeito da temperatura e $\mathrm{pH}$ na atividade da lipase de Rhizopus oryzae.

\begin{tabular}{|c|c|c|c|c|}
\hline Nome & Coeficiente & Erro Padrão & t-calculado & p-valor \\
\hline Média & 27949,842 & 1030,757 & 27,116 & $2,38 \mathrm{E}-08$ \\
\hline $\mathrm{X}_{1}$ & $-7077,552$ & 728,855 & $-9,711$ & $2,5957 \mathrm{E}-05$ \\
\hline $\mathrm{X}_{1}{ }^{2}$ & $-7271,339$ & 814,885 & $-8,923$ & $4,5103 \mathrm{E}-05$ \\
\hline $\mathrm{X}_{2}$ & $-1588,765$ & 728,855 & $-2,180$ & 0,066 \\
\hline $\mathrm{X}_{2}{ }^{2}$ & $-4295,734$ & 814,885 & $-5,272$ & 0,001 \\
\hline
\end{tabular}


Em seguida, foi realizada a ANOVA com nível de significância $\alpha=10 \%$, apresentada na tabela 3 .

Tabela 3 - Análise de variância (ANOVA) no estudo do efeito do pH e da Temperatura na atividade enzimática da lipase de Rhizopus oryzae.

\begin{tabular}{|l|c|c|c|c|c|}
\hline Fonte de Variação & $\begin{array}{c}\text { Soma dos } \\
\text { quadrados }\end{array}$ & $\begin{array}{c}\text { Graus de } \\
\text { Liberdade }\end{array}$ & $\begin{array}{c}\text { Quadrado } \\
\text { Médio }\end{array}$ & Fcalc & p-valor \\
\hline Regressão & 813136791,59 & 4,00 & 203284197,90 & 47,83 & $3,610^{-5}$ \\
\hline Resíduos & 29748897,05 & 7,00 & 4249842,44 & - & - \\
\hline Falta de Ajuste & 28111455,22 & 4,00 & 7027863,81 & 12,88 & 0,031 \\
\hline Erro Puro & 1637441,82 & 3,00 & 545813,94 & - & - \\
\hline Total & 842885688,64 & 11,00 & - & - & - \\
\hline
\end{tabular}

Como Fregressão/resíduos $(47,83)>$ Ftabelado $(2,96)$ e $\mathrm{R}^{2}=96,47 \%$ o modelo pode ser considerado estatisticamente significativo, ou seja, os valores experimentais se ajustam aos valores preditos (Figura 1).

Figura 1 - Valores experimentais e valores previstos para o modelo de atividade enzimática.

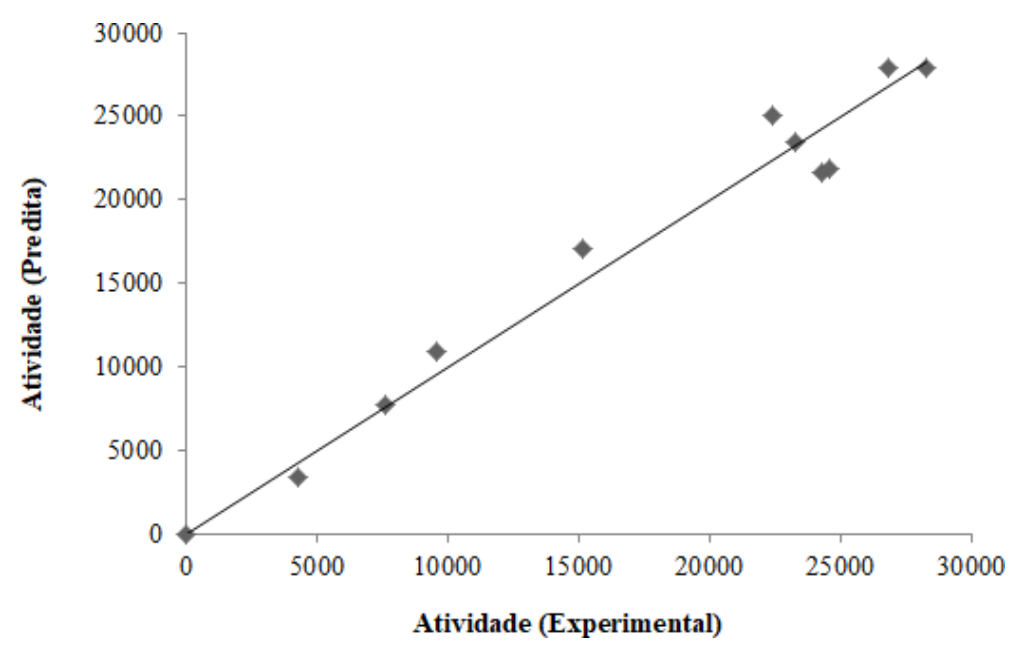

Assim, após a validação do modelo matemático para a variável de atividade enzimática, foram geradas as superfícies de respostas representadas pela Figura 2. 


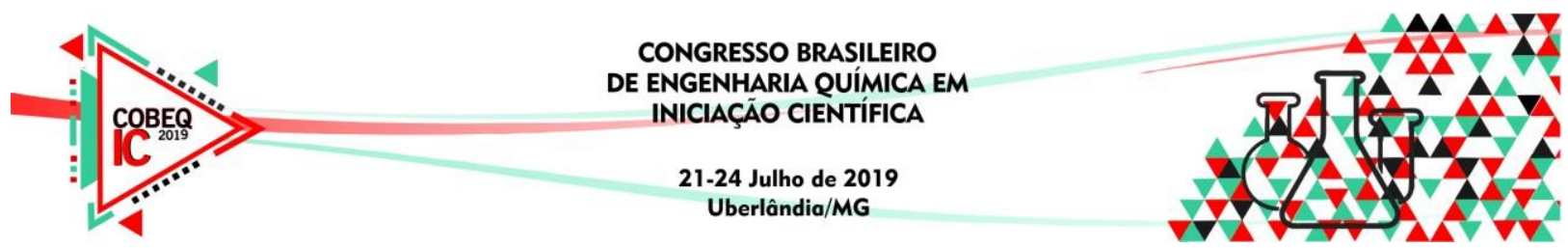

Figura 2 - Superfícies obtidas no planejamento experimental DCCR para a atividade enzimática da Lipase de Rhizopus oryzae como resposta da variação de $\mathrm{pH}$ e Temperatura
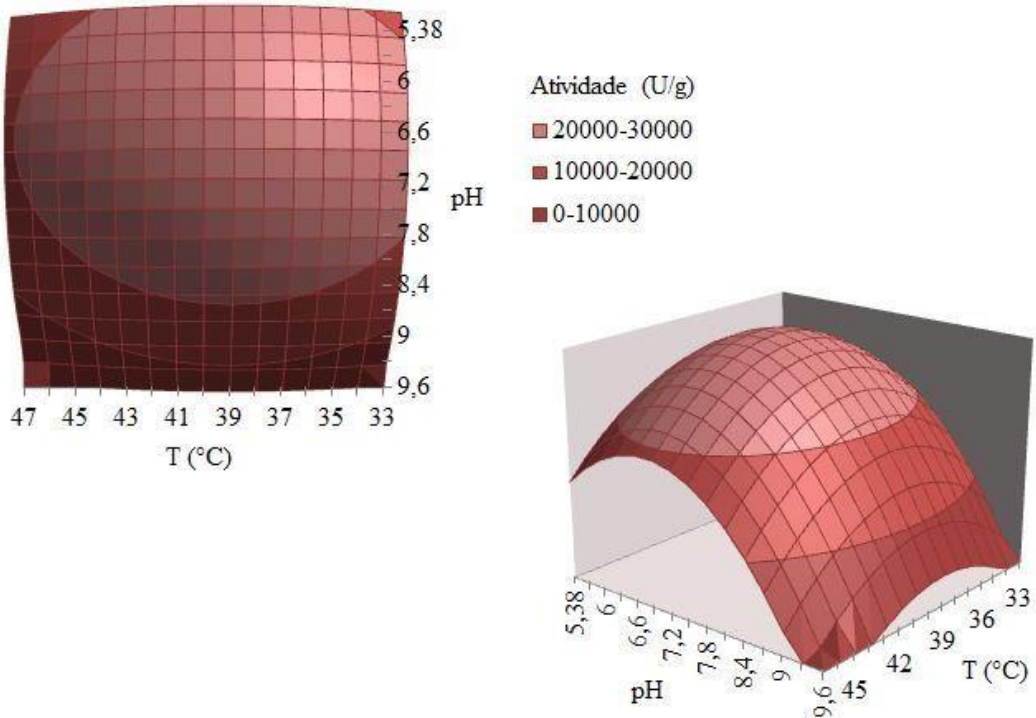

A Figura 2 indica que os valores de maior atividade para a Lipase de Rhizopus oryzae em sua forma livre são obtidos próximos ao ponto central, em que foi utilizada a temperatura de $40^{\circ} \mathrm{C}$ e o $\mathrm{pH} 7,5$. O aumento dos valores de $\mathrm{pH}$ e da temperatura que se distanciam desse ponto, assim como a diminuição, ocasiona uma queda significativa de atividade.

Esse resultado se aproxima do observado no trabalho de HIOL e colaboradores (2000), que obtiveram valores de $\mathrm{pH} 7$ e temperatura $40^{\circ} \mathrm{C}$ como ótimos para a lipase de Rhizopus oryzae, com queda de atividade nas temperaturas superiores e inferiores à $40^{\circ} \mathrm{C}$ e $\mathrm{pH}$ acima e abaixo de 7,5. Além disso, KHARRAT et al (2011) obteve um valor de temperatura ótima de $39^{\circ} \mathrm{C}$ em seus estudos e BEER et al (1998) valores ótimos de $\mathrm{pH}$ na faixa de 7, pra o mesmo biocatalisador. Ambos descreveram decaimento de atividade para valores inferiores ou superiores aos ótimos.

Portanto, de acordo com as superfícies de resposta e as predições representadas pelo modelo da equação 1 , o ponto que apresenta a melhor resposta é o de temperatura igual a $39^{\circ} \mathrm{C}$ e $\mathrm{pH} 6,8 \mathrm{com}$ um valor de atividade previsto em $29818,79 \mathrm{U} / \mathrm{g}$.

\section{CONCLUSÃO}

A lipase de Rhizopus oryzae livre apresentou características comuns aquelas descritas na literatura em relação aos valores ótimos de pH e temperatura. Assim, com a análise 


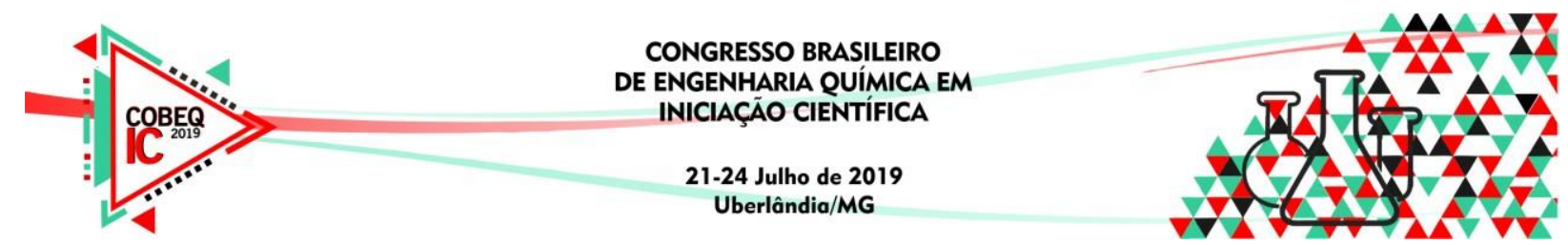

estatística foi possível caracterizar o biocatalisador e, a partir do modelo matemático gerado, prever quais seriam as melhores condições de aplicação dessa lipase. Por fim, os objetivos desse trabalho foram alcançados, já que foi possível realizar a caracterização da enzima livre utilizando planejamento experimental do tipo DCCR.

\section{AGRADECIMENTOS}

Fundação de Amparo à Pesquisa do Estado de São Paulo, FAPESP (2018/10194-0 e 2017/11482-7).

\section{REFERÊNCIAS BIBLIOGRÁFICAS}

BASSAN, N. Modificação enzimática de óleos vegetais visando à obtenção de triglicerídeos dietéticos através do emprego de reatores de tanque agitado e leito fixo. 2017. 95 f. Dissertação (Mestrado) - Curso de Alimentos e Nutrição, Universidade Estadual Paulista “Júlio de Mesquita Filho”, Araraquara, 2017.

BEER, H. D., MCCARTHY, J. E., BORNSCHEUER, U. T., SCHMID, R. D. Cloning, expression, characterization and role of the leader sequence of a lipase from Rhizopus oryzae. Biochimica Et Biophysica Acta (bba) - Gene Structure And Expression, v. 1399, n. 2-3, p.173-180, ago. 1998.

CIPOLATTI, E. P. Imobilização de Lipases em Suportes Poliméricos. 2015. 177 f. Tese (Doutorado) - Curso de Engenharia de Alimentos, Universidade Federal de Santa Catarina, Florianópolis, 2015.

HIOL, A., et al. Purification and characterization of an extracellular lipase from a thermophilic Rhizopus oryzae strain isolated from palm fruit. Enzyme And Microbial Technology, [s.1.], v. 26, n. 5-6, p.421-430, mar. 2000.

KHARRAT, N., SANA, M. Y. B. A.; GARGOURI, Y. T.; KARRA-CHÂABOUNIA, M. Immobilization of Rhizopus oryzae lipase on silica aerogels by adsorption: Comparison with the free enzyme. Process Biochemistry, [s.1.], v. 46, n. 5, p.1083-1089, maio 2011.

PAULA, A. V. Reestruturação da gordura de leite por interesterificação enzimática empregando lipase imobilizada: otimização das condições reacionais e operacionais. 2011. 212 f. Tese (Doutorado em Ciências) - Escola de Engenharia de Lorena, Universidade de São Paulo, Lorena/SP, 2012. 